\title{
Integration of resiliency measures into flood risk management concepts of communities
}

\author{
N. Manojlovic \& E. Pasche \\ Department of River \& Coastal Engineering, \\ Hamburg University of Technology, Germany
}

\begin{abstract}
Based on the recent flood events in Europe and following the latest scientific reports on climate change IPCC, and urban development EEA it becomes evident that the areas in Northern and Middle Europe are becoming increasingly affected by flooding. In the changing environment, the conventional flood protection measures are not providing sufficient protection level and are very cost intensive. New strategies to cope with flooding have to be developed and implemented to adapt the communities to climate change in an adequate way. This paradigm shift from "flood fighting" to "living with floods" reflects the current EU Flood Policy formulated in the EU Flood Directive and adopted by national laws. Especially vulnerable are urban areas where the economic growth, in case of extreme flood events, can be irreversibly disrupted. Other than applying mere conventional protection, the innovative resilience concepts should be considered that integrate the building environment into flood protection by improving the resilience performance of the urban fabric and build capacity of stakeholders. In order to optimise the performance of flood protection, as alternative to resiliency measures for each household separately, integrative solutions for the area/ city quarter are to be considered. In general, which level of integration is to be implemented depends technical, economic and socio-political criteria. The adopted integration level can in any case be supported by the adhock measures that can serve as an intermediate solution and initial phase for active stakeholder involvement. For the historic area of the City of Lauenburg that was recently severely affected by flood events of the river Elbe (2002, 2006), resilience concepts have been developed. Without a solution for flood protection, sustainable development of the city, primarily focused on tourism, cannot be achieved. Different resilience solutions, based on different levels of integration and adaptability are presented and discussed.
\end{abstract}

Keywords: flood resilience, resilience measures, built environment, adaptability. 


\section{Introduction}

The extent and consequences of recent flood events in Europe and worldwide (Europe 2002, 2006, New Orleans 2005) showed that the existing flood defence structures do not guarantee sufficient protection level of people and properties. Considering the uncertainty of future conditions shaped by main drivers of urban development such as climate change (IPCC [1]) and rapid urbanisation (EEA [2]), the situation is getting even more severe. In this unfavourably changing environment, a substantial rethinking of the existing strategies and paradigm shift from the traditional approaches is required in order to cope with future flooding in an adequate way. New strategies that target at a more holistic approach of flood risk management and consider the uncertainties of future development should be developed. The most important aspect of those new strategies is their adaptability and flexibility. The strategy, where the solutions can be gradually implemented, giving the time to the system to develop capacity for the changes, becomes an imperative for managing floods in urban areas. This paradigm shift in flood management triggers also a demand for active involvement of all stakeholders, especially residents in flood prone areas. They have to develop capacity to contribute adequately to flood protection of their properties. Recognising the necessity for systematic response to this increased flood risk, the "Directive of the European Parliament and of the Council on the assessment and management of floods" (short: EU Flood Directive) was released and finally adopted on September 18th, 2007 [3]. Driven by this EU initiative many countries adapted or released new water policies to cope with floods. For example, in Germany those regulations are brought forward within the Flood Control Act (FCA).

This paradigm shift implies considerable changes for the communities that got entrapped by the way they have been practicing flood risk management for decades (Ashley et al. [4]). They are now challenged to change their policies towards more integrated flood management strategies. Those strategies should follow the concept of "living with floods" rather than "flood fighting". Current practice in communities shows rather low awareness of the possibilities of such strategies. In general they are applied only if none of the structural solutions due to economic or technical reasons is feasible. Such policy creates unfavourable conditions for stakeholder involvement. It usually starts very late when it is already difficult to shift form expectations of total protection promised by the conventional measures, to the situation where they have to be pro active. Such an example is the community Wertheim, Germany, on the river Main, where due to local conditions it was not possible to protect the frequently flooded historic area in a conventional way. Finally, the community decided to "live with flood". Even with financial incentives, the implementation of the concept is moving slowly accompanied with low interest of the stakeholders Moser [5]. That could be explained by too late consideration of more integrative solutions and retarded initiation of the capacity building process. In general, in communities in flood plains in the Middle and Northern Europe (e.g. Germany) different attitudes towards those new strategies could be identified. Frequently flooded 
communities such as the ones in the floodplain of the river Moselle or Rhine, Germany, there is a certain level of adaptation of built environment, as the problem has been known for a long time (Pasche et al. [6]). But those changes were made as a reaction to the previous hazards, by adopting experiential flood levels from the past and not always taking care about the uncertainty of the future conditions. In the areas protected by dykes, the challenge for the community is to define strategies to cope with the residual risk that will probably increase in the future (Nehlsen et al. [10]). Considering the communities in the floodplains in Germany and Europe wide, an integrative approach that would from the beginning consider all flood mitigation options including "living with floods" strategies and at the same time build capacity of stakeholders to be able to act adequately, has hardly been identified.

The focus of this paper is to discuss possible flood mitigation strategies for communities based on the "living with floods" principle and demonstrate their adaptability. The aspect of capacity building of stakeholders, that is always combined with these strategic measures has been considered, but the methodology and strategies for capacity building as well as political and social aspects are not discussed.

\section{Strategies to cope with flooding}

Strategies promoting the "living with floods" paradigm are based on the resilience principle. The term resilience can be defined as [the ability of a system/community/society/defence to react to and recover from the damaging effect of realised hazards] (Flood Site [7]). Applying the source- receptorpathway -consequence model (S-P-R-C), e.g. Flood Site [7], the Flood resilience measures (FRM) are defined as the measures that improve the resiliency of the receptor and/or reduce the exposure to flooding (Pasche et al. [8]), where the urban fabric and people with their activities on the flood plain are considered as receptor. The FRM aiming at increasing the resiliency of the built environment are referred to as flood preparedness (Pasche et al. [8]). By those measures, the resilience of the buildings can be improved either by preventing floodwater entering the building (dry proofing) or by applying waterproof materials and raising inventory and services above expected flood level, (wet proofing) (Manojlovic and Pasche [9]). In the case of dry proofing floodwater is kept out of the building. Those techniques are generally more cost-intensive than the wet proofing ones and always carry a certain failure risk, as the stability of the building can be jeopardised through the increased water pressure. By applying wet proofing measures floodwater is not prevented from entering the building, but the building is adapted to flooding by applying water resistant materials or adapting the occupancy of the building (e.g. basement is not used for living) (Manojlovic and Pasche [9]). In general, the objective of those measures is not to achieve total protection of the properties in flood prone areas, but to provide an adaptable protection basis that can be enhanced depending on the future conditions. A certain restriction in comfort can usually not be avoided and the residents should build capacity to cope with this requirement. 
Adaptable solutions (protection) are the ones that can be extended (changed) to fulfil the requirements of the future development applying reasonable effort. The requirements and the reasonable effort have to be defined for the given conditions. The principle of adaptability can be described on the example of the controlled flooding of a building. For the lower part of the buildings (basements) the controlled flooding strategy is applied, while the upper potentially affected parts of the building are dry proofed (Manojlovic and Pasche [9]). The water pressure to the external walls is kept below the critical load by a pump in a sump and is regulated by pressure sensors. In the flooded building parts waterproof materials are applied and services are raised, in order to minimise the damage to building fabric. This strategy is not recommendable if the difference between the level in basement and the floodwater outside is more than $1.5 \mathrm{~m}$. For pressure difference greater than $1,5 \mathrm{~m}$ in most cases the stability of a building cannot be guaranteed due to strong buoyancy forces. In case of future scenarios that favour more extreme conditions, such strategy can be adapted by additional pumps for keeping the water pressure difference below the critical level with further enforcement and anchoring of the building (Fig. 1). Finally, depending on the future scenarios by exhausting the adaptable capacity of the strategy at a certain point this system has to be redesigned.

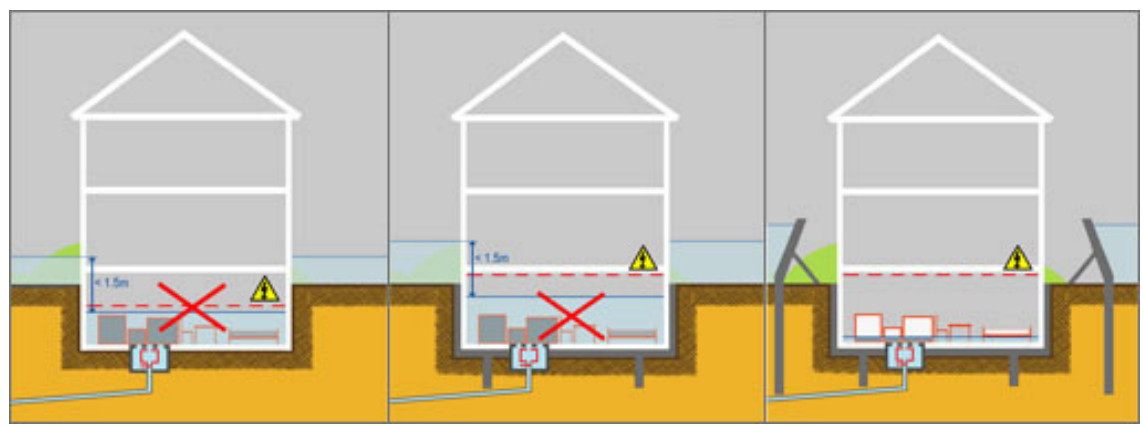

Figure 1: Adaptability of controlled flooding concept considering climate change scenarios (now, projection 1-adaptation, projection 2redesign).

Such measures should be the basis for development of the flood management strategies that can cope with the uncertainties in an adaptable manner. Considering opportunities for communities to cope with flood problem now and in the future, the following strategies can identified:

\subsection{Protection of single properties separately}

In this strategy, each owner is responsible for the measures taken on his own property. The measures should be planned according to already presented adaptable principle (Fig. 1). Each house is protected separately without considerations of the others. Although within this strategy, there is no organised 
initiative or collective measures for flood protection, the communities should stimulate and supervise the flood proofing of built environment. It can be achieved by provision of financial incentives and consultancy to the residents, either by the experts on site or by means of modern technology and media, such as FLORETO (Manojlovic and Pasche [9]). EU Flood Directive [3] defines the guidelines for risk mitigation that are to be adopted on the community level. The restrictions and requirements for built environment for certain areas should be included into development plans. In order to achieve more efficiency in planning and implementation of the measures, alliances of local authorities, standardisation agencies and insurance companies should be built with the idea to certify appropriately proofed buildings with a "flood proof seal".

\subsection{Clustering of the adjacent buildings (neighbourhoods)}

Next level of resilience strategies with higher level of coordination can be achieved by clustering the neighbourhoods with the aim to develop synergetic effect, i.e. reducing costs and improving the efficiency of the flood mitigation. This strategy is applicable only in case it is possible to create such clusters depending on the intensity of urbanisation, hydrological or social conditions. In such clusters the risk due to failure is borne by several parties that is of high importance for application and maintenance of, for example, dry proof measures (installing of flood barriers etc) or in case of vulnerable groups (old or disabled people). The parties involved need to be legally bound (e.g. via contract), where the responsibilities related to implementation, maintenance of the measures and operation in case of flooding have to be specified.

\subsection{Connecting buildings to resilience frontline}

The highest level of coordinated resilience strategy is achieved by closing the front to the watercourse. The gaps between the buildings should be closed either by permanent constructions, demountable barriers or a combination of both. As in the previous cases, the adaptability of the solutions for built environment should be considered as shown in Fig. 1. Adaptations of the drainage system are usually required both on private and community level. In the broader sense this strategy can be understand as a cluster solution for a wider area (e.g. city quarter), but this level of integration requires considerably higher logistical effort. The main responsible is the community that should take care of design, implementation and maintenance of the measures. Proper installation of the demountable measures or enforcements of the frontline can require access to the private properties to which the residents have to consent. As this strategy requires the highest involvement level of stakeholders and mutual trust, capacity building of stakeholders has to start in an early phase. In this strategy the risk due to failure is spread on the whole community but on the other hand, the system functions as one entity and for its success all its elements have to work properly.

Furthermore, such systems can have influence on the groundwater migration and processes in the ground, so that additionally to resilience measures 
geotechnical improvements can be required. To a certain extent this strategy can be perceived as a combination of structural and resilience measures. Still it is to be considered as resilience strategy as its notion corresponds to "living with water" idea.

\subsection{Combination of conventional and resilience measures}

In case that the structural measures already exist in the area, or if due to local situation it is impossible to avoid them, they can be combined with the resilience measures. The resilience measures can bear the uncertainty of the future development and as such can be applied instead of raising dykes or increasing volume or polders. An example of such combination is a compartment strategy (Nehlsen et al. [10]).

The process of integration can be time intensive and the "ad-hoc" solutions should be prepared for the case that the flood occurs before the total implementation has been performed. Such solutions should imply rapid measures that can be achieved in a short time (sealing the openings or installation of pumps) and should involve stakeholders.

\subsection{Decision making (DM)}

Which strategy will be adopted can be decided within the decision making process as depicted in Fig. 2. Additionally to the traditional way of thinking, an approach that considers climate change projections can be applied.

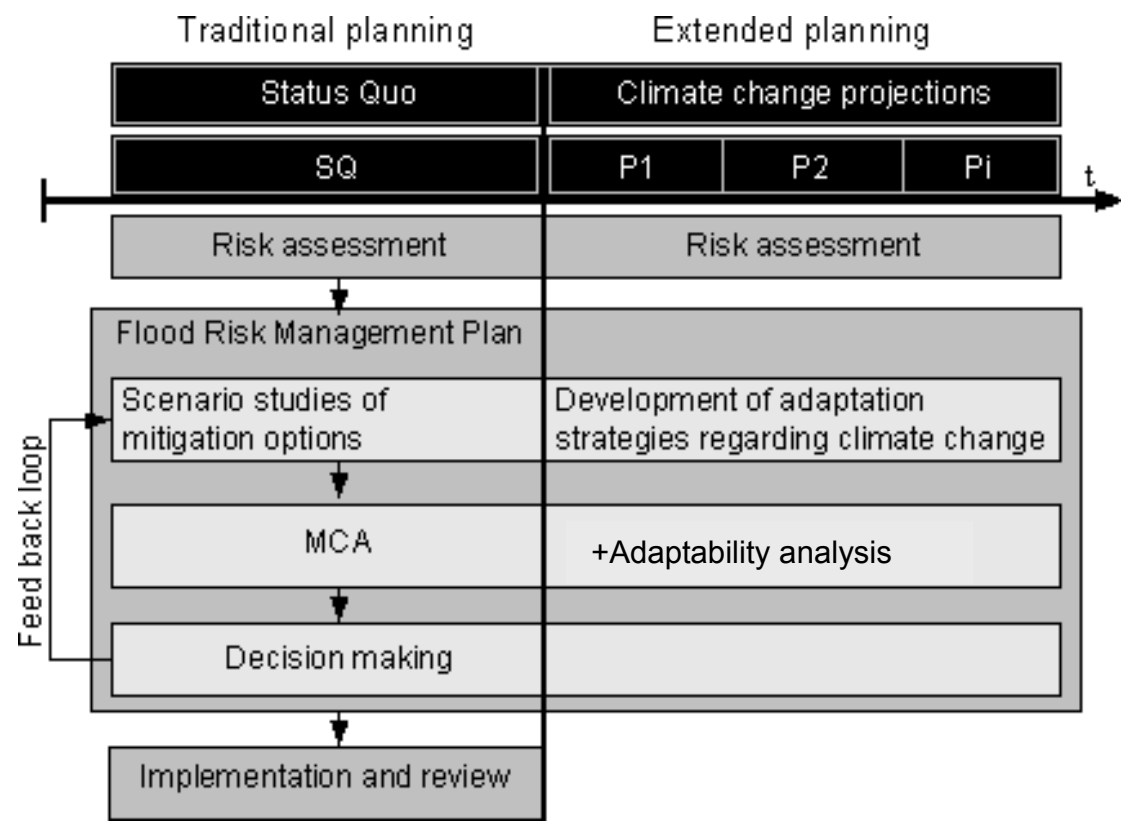

Figure 2: Decision making process with and without considerations of future climate change scenarios. 
As the first step in both approaches, risk assessment according to the EU Flood Directive [3] has to be performed. Depending on approach, it implies either only status quo situation or is extended to the analysis of the projected scenarios. For definition of Flood Risk Management Plan, possible options for flood risk mitigation have to be considered. In the extended concept, adaptation strategies regarding climate change are analysed and their potential to cope with future risks is discussed. Those solutions are analysed within MCA based on selection criteria as given in Table 1 .

Table 1: $\quad$ Selection criteria for multi criteria analysis (MCA).

\begin{tabular}{|c|c|c|c|}
\hline Category & \multicolumn{3}{|c|}{ Criteria } \\
\hline $\begin{array}{l}\text { Cost } \\
\text { effectiveness }\end{array}$ & Costs of investment & Maintenance costs & Cost-Benefit ratio \\
\hline $\begin{array}{l}\text { Changes in } \\
\text { hydrologic } \\
\text { regime }\end{array}$ & $\begin{array}{l}\text { Loss of retention } \\
\text { capacity }\end{array}$ & $\begin{array}{l}\text { Changes in the river } \\
\text { morphology }\end{array}$ & \\
\hline $\begin{array}{l}\text { Safety and } \\
\text { reliability }\end{array}$ & $\begin{array}{l}\text { Logistical } \\
\text { requirements }\end{array}$ & $\begin{array}{l}\text { Controllability of the } \\
\text { seepage water }\end{array}$ & $\begin{array}{l}\text { Controllability of } \\
\text { protection system } \\
\text { (design for failure) }\end{array}$ \\
\hline $\begin{array}{l}\text { Protection } \\
\text { quality }\end{array}$ & $\begin{array}{l}\text { Accessibility of } \\
\text { buildings during } \\
\text { flood event }\end{array}$ & $\begin{array}{l}\text { Maintenance of the } \\
\text { municipal sewerage } \\
\text { system }\end{array}$ & $\begin{array}{l}\text { Impact on } \\
\text { drainage system }\end{array}$ \\
\hline $\begin{array}{l}\text { Impact on } \\
\text { riverscape }\end{array}$ & $\begin{array}{l}\text { Changes of the town } \\
\text { silhouette }\end{array}$ & $\begin{array}{l}\text { Changes of the built } \\
\text { environment }\end{array}$ & $\begin{array}{l}\text { Preservation or } \\
\text { cultural and } \\
\text { natural heritage }\end{array}$ \\
\hline
\end{tabular}

As the final step, the implementation of adopted strategy and review is performed.

\section{Application of concept}

Different integration strategies of resiliency measures have been applied for the case of the historic area of the City of Lauenburg, Germany.

Lauenburg is a town situated in Schleswig-Holstein, Germany on the northern bank of the river Elbe, east of Hamburg. The town was founded in 1209 [12] and nowadays its historic area is well known for its century timber framed buildings and the beauteous riverbank silhouette. The urban structure is rather dense, forming a tight front to the river Elbe leaving small gaps between the buildings, so called "twiete" as shown in Fig. 3. The recent flood events on the river Elbe in 2002 and 2006 affected considerably the historic area devastating the historic building fabric and causing financial losses to local economy mostly based on tourism. Facing the situation of increasing probability of flooding on one side and willingness to preserve the historic area on the other, there is a need for immediate action incorporated into the changes of communal flood risk management. Strategies based on the resilience principle may be an answer to the increasing flood problem. 

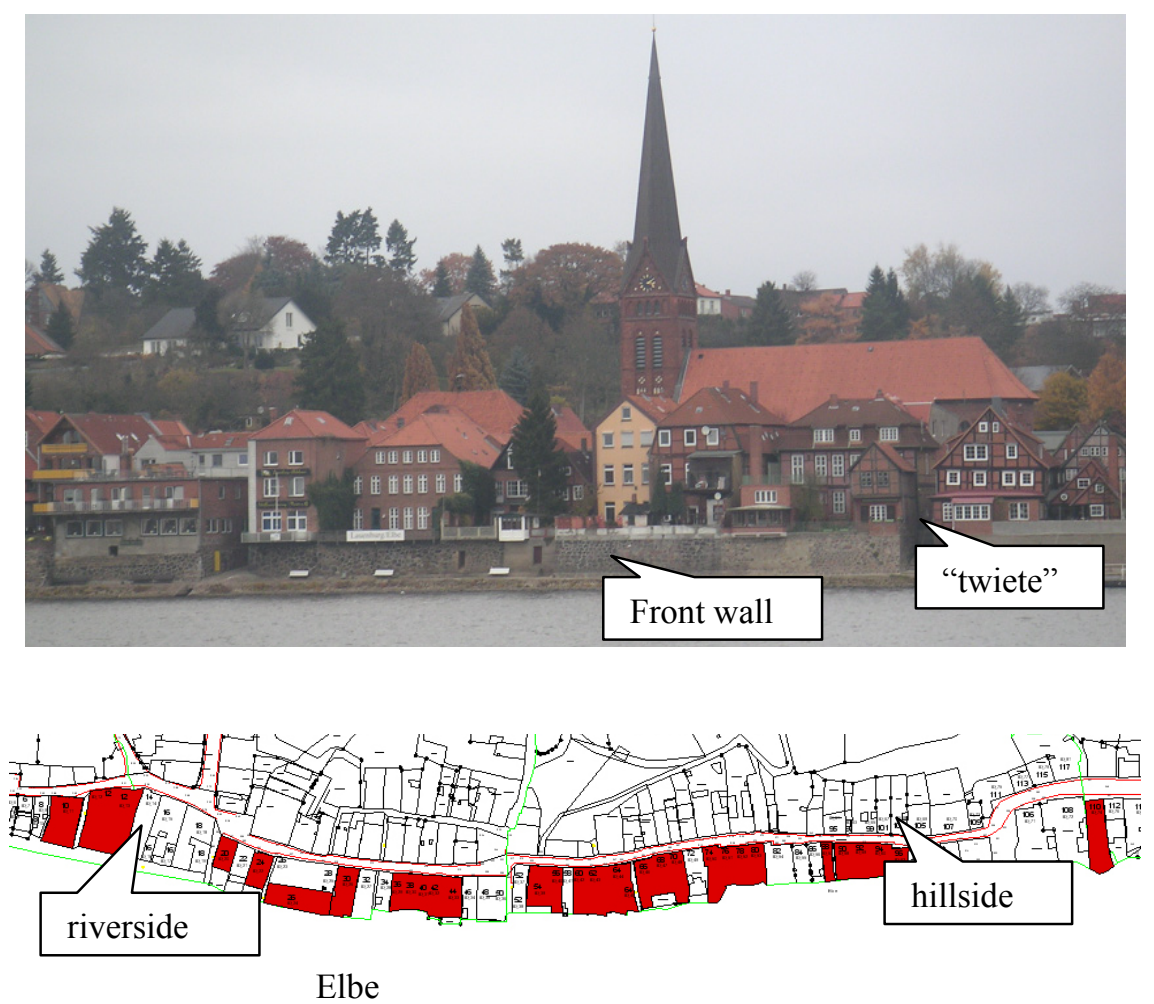

Figure 3: The riverbank silhouette of the Lauenburg historic area with the corresponding plan view (highlighted buildings are affected by 25 year flood).

\subsection{Decision making (DM)}

The strategies were developed within the decision making process as given in Fig. 2. The stakeholders were from the beginning included into the DM process (Pasche and Manojlovic [11]).

\subsubsection{Risk assessment}

Based on the flood probability assessment for status quo and future scenarios, the range of the design flood from 9,40 $\mathrm{m}$ a.s.l. (status quo) to 9,70 $\mathrm{m}$ a.s.1. (p3) has been derived. Risk assessment showed that a certain resilience capacity already exists in the area, as the city has long flood history and some adaptation measures such as wet proofing of basement have already been applied. Starting from the 50-year flood the expected damage steeply increases, clearly indicating this capacity level. The annual flood damage of $32.000 € /$ a does not reflect the real situation and can hardly be taken as a decisive criteria for planning, as in case of extreme events the development of the area can be irreversibly disrupted and recovering can take long time (Nehlsen et al. [10]). Therefore, for planning 
of mitigation strategies, the adaptability potential of resilience strategies have to be considered.

\subsection{Flood risk management plan}

Different mitigation scenarios with different adaptability levels have been developed and their suitability for the given conditions discussed based on the defined criteria. Decision making process is currently running.

\subsubsection{Protection of single properties separately (S1)}

Each of the properties is protected individually applying the controlled flooding concept. Analysis on site showed potential problem to access some building parts from the outside as the buildings are very close to each other. It can make dry proofing more difficult and consequently has an impact on costs. This fact can influence the adaptability of this solution, as this problem will get even more severe in the future. The inspection on site also showed that houses have lots of openings, some of them having direct connection to the river Elbe. In more extreme conditions in the future, it can generate an increasing problem. Also, elevation of some buildings is rather low, even $2-3 \mathrm{~m}$ below the design flood, that creates too high pressure for already decaying historic fabric. As the frontline to the river Elbe is not closed, floodwater can reach the street side of the front buildings, so that the openings on the street side and buildings on the hillside have also to be protected. (Fig. 2) Apart from additional costs for these measures, floodwater on streets disables traffic and hinders access to homes.

\subsubsection{Clustering of the adjacent buildings (neighbourhoods) (S2)}

Due to the intensity of urbanisation, the clustering of the neighbourhoods can be a reasonable option. In this way the implementation of dry proofing measures can be improved as the clusters can be defined in a way that access to the building parts that should be dry proofed, is made possible (Fig. 4). Still floodwater can reach the streets, creating the same problem as in strategy 1.

\subsubsection{Connecting buildings to resilience frontline (S3)}

The front buildings can create a chain closing the front to the Elbe, by closing the gaps between the buildings with demountable barriers with sheet piling as shown in Fig. 4 and partly raising the front wall to the Elbe (Fig. 2). Also, the front wall has to be improved by sealing measures, so that the floodwater reaching the basements can be controlled. Due to the fact that the streets will not be flooded, but the water will be pumped out of the basements and conveyed, adaptations in the municipal drainage network are necessary. Some of the properties discharge storm water through pipes directly to the river Elbe. Those pipes have to be revised and reconnected to the municipal drainage network.

Considering the given conditions on site, an extended version of this concept has also been considered. In order to reduce the risk due to groundwater seepage, a soil injection can be applied in the front line to the river Elbe. Apart from the fact that the soil injection is very cost intensive, it will have a direct impact on the river and groundwater processes, so that further geotechnical investigations are required. 

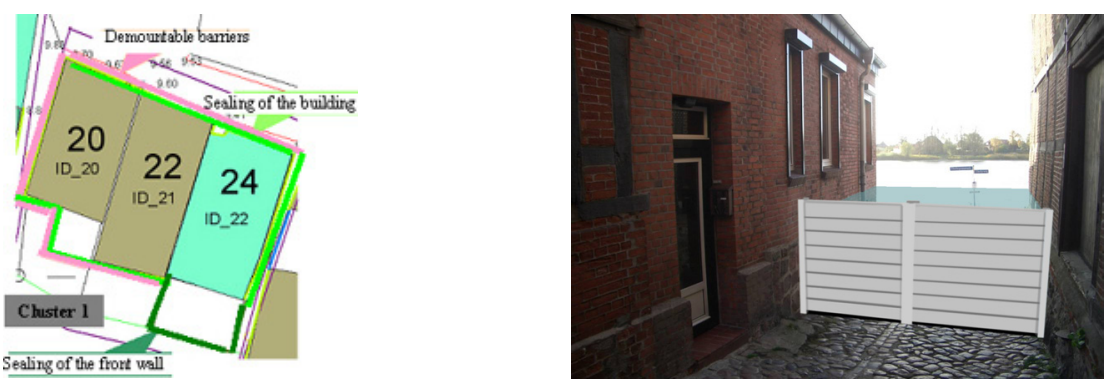

Figure 4: Left: Clustering the adjacent buildings. Right: closing gaps between the buildings [11].

\subsubsection{Combination of conventional and resilience measures (S4)}

Due to proximity to the watercourse and estimated extreme costs of conventional measures that cannot be provided, conventional protection measures such as dykes and walls are hardly to be considered.

\subsection{MCA and DM with adaptability analysis}

The MCA is performed for the status quo and future projections. The outcomes are given in Table 2. Further, the solutions are discussed in terms of their adaptability. The $\mathrm{S} 1$ shows rather low adaptable potential, as the implementation and operational difficulties at present (e.g. complicated dry proofing and consequently higher costs) will continue in the future. Although some improvements (accessibility to the building parts, cost reduction for status quo) can be identified by the S2, it still has some shortcomings that are high costs for future adaptation of the built environment or uncertainties of changes in social environment (e.g. changing ownership). The S3 shows higher adaptability potential than the previous two. For future requirements, the front line can be further raised by demountable walls without permanently influencing the town silhouette. The houses can be protected according to the principle shown in Fig. 1. Also, the quality of the mitigation does not change, as the streets are kept dry and houses remain accessible as well as the houses on the hillside, which is a big advantage for already decaying historic building fabric and will not have impact on further costs. However, the adaptable capacity of this strategy also has its limits and at a certain point it has to be redesigned.

Table 2: $\quad$ MCA for the resilience strategies applied to the case Lauenburg.

\begin{tabular}{|l|l|l|l|l|}
\hline Criteria & 1 & 2 & 3 & 4 \\
\hline Cost effectiveness (benefit- cost ratio) & 0.2 & 0.42 & 0.37 & $<<$ \\
\hline Changes in hydrologic regime & 0 & 0 & $0(-)$ & - \\
\hline Safety and reliability & -- & - & + & +- \\
\hline Protection quality & -- & - & ++ & + \\
\hline Impact on riverscape & 0 & 0 & + & -- \\
\hline
\end{tabular}




\section{Discussion and outlook}

The resilience strategies can be an answer to increasing flood risk and uncertain future conditions due to their adaptability potential. Adaptability is an important aspect and its consideration in current planning could improve future development in flood prone areas as shown on the Lauenburg example. Performed analysis for given condition creates a platform for currently running decision-making process. For future analysis, an adaptability index can be defined indicating the potential of measures/strategies for application in future conditions. Further, decision support systems for strategic planning on community level that consider climate change projections should be developed. The existing expert systems, such as FLORETO [9] can be a good basis. Capacity building of stakeholders should accompany the transition phase, so that communities can maximally benefit from those adaptable resilience strategies in the future.

\section{References}

[1] IPCC (Intergovernmental Panel on Climate Change) (2007): Climate Change 2007 - The physical science basis, Working Group I Contribution to the fourth assessment report of the IPCC, www.ipcc.ch

[2] European Environment Agency (EEA) www.eea.europa.eu

[3] Directive 2007/60/EC of the European Parliament and of the Council of 23 October 2007 on the assessment and management of flood risks, 2007 ec.europa.eu/environment/water/flood_risk/key_docs.htm

[4] Ashley, R., Newman, R., Molyneux-Hodgson, S., Barriers to mitigation of flood risk in the east end of Glasgow using non-structural responses, ERA NET CRUE- SUCA National Project Report, 2007

[5] Moser M. Personal communication, 15 May 2007, Regional Council, Baden Würtenberg, Germany

[6] Pasche E., Geissler, T. R, New Strategies of Damage Reduction in Urban Areas Prone to Flood, Urban Flood Management; eds: Szöllösi-Nagy, A., Zevenbergen, C. Blakema Publishers. Leiden/ London/New York, 2004

[7] Flood Site, Language of Risk, www.floodsite.net

[8] Pasche, E., Lawson N., Ashley, R., Schertzer, D., Risk Assessment and Risk Management in Small Urban Catchments, ed: CRUE Funding Initiative on Flood Risk Management Research, 2008

[9] Manojlovic, N., Pasche, E., FLORETO-Web Based Advisory for Flood Mitigation Strategies for Existing Buildings, Advances in Urban Flood Management, Taylor \& Francis Group London, UK, pp. 359-382, 2007

[10] Nehlsen, E., Wilke, M., Goltermann, D., Pasche, E., Flood Mitigation Using Cascading Dike System, Proc. of the 8. Forum DKKV/CEDIM: Disaster Reduction in Climate Change, University of Karlsruhe, 2007

[11] Pasche, E, Manojlovic, N., Flood mitigation concept for the historic area of the City of Lauenburg, Project Report, 2007

[12] City of Lauenburg, Germany jubilaeum2009.lauenburg.de 